\title{
TRADUÇÃO
}

\section{ATIVIDADE E CONSCIÊNCIA ${ }^{1}$}

\author{
Alexei Nikolaevich Leontiev \\ Tradução de Marcelo José de Souza e Silva ${ }^{2}$
}

Ao examinar este problema, o primeiro ponto que devemos considerar é a questão da significância da categoria atividade em qualquer interpretação de como a consciência humana é determinada.

Existem duas abordagens para esta grande questão. Uma delas postula a dependência direta dos fenômenos da consciência nas várias influências exercidas sobre os sistemas receptores do homem. Esta abordagem foi expressa com clássica clareza na psicofísica e fisiologia dos órgãos sensoriais do século XIX. A principal tarefa da pesquisa naqueles dias era estabelecer a dependência quantitativa de sensações, independente dos elementos da consciência, nos parâmetros físicos dos estímulos afetando os órgãos sensoriais. Estas pesquisas eram então baseadas no padrão "estímulo-resposta".

As limitações desta abordagem residem no fato de que assume, de um lado, coisas e objetos, e, do outro lado, um sujeito passivo influenciado por eles. Em outras palavras, esta abordagem ignora o elemento significante das verdadeiras relações do sujeito com o mundo objetivo; ignora sua atividade. Tal abstração é, naturalmente, admissível, mas somente dentro de limites de um experimento com a intenção de descobrir certas propriedades de certos processos mentais. $\mathrm{O}$ momento que alguém vai além desses limites estreitos, entretanto, percebe a inadequação desta abordagem, e foi

\footnotetext{
${ }^{1}$ Este artigo foi publicado em russo na revista Voprosy filosofii (1972, n. 12, p. 129-140) e em inglês no livro Filosofia na URSS: Problemas do Materialismo-Dialético (Moscou, 1977, p. 180-202). Leontiev enfatiza o caráter social da consciência humana, tanto no nível coletivo quanto no nível individual, em contraposição às concepções positivistas de uma influência minimalista do ambiente. Ele procura superar a abordagem dualista "sujeito-objeto" (ou "estímulo-resposta") propondo a unidade de análise sujeitoatividade-objeto, entendendo a atividade humana como a substância da consciência, sendo esta última um movimento interno composto por "elementos formativos", como o significado objetivo e o significado pessoal, e que são orientados a um movimento geral da atividade que afeta a vida real do indivíduo na sociedade. Original disponível no Marxists Internet Archive. Direitos de Reprodução: (oc) EY-sa licenciado sob uma licença Creative Commons.

${ }^{2}$ Possui graduação em Farmácia e é Mestre em Educação pela UFPR. Atualmente é doutorando em Medicina pela USP. Pesquisador do grupo "Núcleo de Estudos em Saúde Coletiva" (UFPR), atuando na linha de pesquisa "Estudos Marxistas em Saúde"; estudante do grupo "Necessidades, Práticas e Profissionais em Saúde em Abordagem Interdisciplinar" (USP), atuando na linha de pesquisa "Trabalho, Educação e Comunicação em Medicina e em Saúde”. E-mail: marcelojss@gmail.com.
} 


\section{Tradução - ATIVIDADE E CONSCIÊNCIA}

Aleksei Nikolaevich Leontiev

isso que compeliu os primeiros psicólogos a explicar os fatos psicológicos com base em forças especiais, tais como as da apercepção ativa, intenção ou vontade interior etc., isso quer dizer, apelar para a natureza ativa do sujeito, mas somente em uma forma mistificada, interpretada idealisticamente.

Existiram muitas tentativas de superar as dificuldades teóricas criadas pelo postulado de imediaticidade subjacente à abordagem que acabamos de mencionar. Por exemplo, é enfatizado que os efeitos das influências externas são determinados não imediatamente pelas próprias influências, mas dependem de suas refrações pelo sujeito. Em outras palavras, atenção é concentrada no fato que causas externas agem através do meio de condições internas. Mas esta noção pode ser interpretada de várias maneiras, dependendo do que se entende por condições internas. Se são tomadas para significar a troca de estados internos do sujeito, a noção nos oferece nada de essencialmente novo. Qualquer objeto pode mudar seus estados e assim se manifestar de diferentes maneiras em sua interação com outros objetos. Pegadas aparecem em chão macio, mas não em chão duro; um animal faminto reage à comida diferentemente de um que está bem alimentado; a reação de uma pessoa alfabetizada a uma carta é diferente da de um analfabeto. É outra questão se por "condições internas" entendemos as características especiais dos processos que estão ativos no sujeito. Mas então a questão principal é o que estes processos são que mediam as influências do mundo objetivo refletido no cérebro humano.

A resposta básica para esta questão reside no reconhecimento de que estes processos são aqueles que realizam uma vida verdadeira da pessoa no mundo objetivo pelo qual ela está cercada, seu ser social em toda sua riqueza e variedade de suas formas. Em outras palavras, estes processos são sua atividade.

Esta proposição requer a próxima definição, de que por atividade entendemos não a dinâmica dos processos fisiológicos, nervosos, que realizam esta atividade. Uma distinção deve ser traçada entre a dinâmica e estrutura dos processos mentais e da linguagem que os descreve, por um lado, e a dinâmica e estrutura da atividade do sujeito e a linguagem os descrevendo, por outro.

Assim, ao lidar com o problema de como a consciência é determinada, somos confrontados com a seguinte alternativa, tanto aceitar a visão implicada no "axioma da imediaticidade", i.e., proceder de um padrão "objeto-sujeito" (ou o padrão "estímuloresposta”, que é a mesma coisa), ou proceder de um padrão que inclui um terceiro vínculo conectivo - a atividade do sujeito (e, correspondentemente, seus meios e modo

\begin{tabular}{|c|c|c|c|c|}
\hline Qevista Dialectus & Ano 2 & n. 4 & Janeiro-Junho 2014 & p. $184-210$ \\
\hline
\end{tabular}


de aparecimento), um vínculo que media suas interconexões, isso quer dizer, proceder do padrão "sujeito-atividade-objeto".

$\mathrm{Na}$ forma mais geral, esta alternativa pode ser apresentada como segue. Ou tomamos a posição de que a consciência é determinada diretamente por coisas e fenômenos que rodeiam o sujeito, ou postulamos que a consciência é determinada pelo ser, que, nas palavras de Marx, não é nada que senão o processo da verdadeira vida das pessoas.

Mas o que é essa verdadeira ou real vida das pessoas?

Ser, a vida de cada indivíduo é feita da soma total ou, para ser mais exato, um sistema, uma hierarquia de atividades sucessivas. É em atividade que a transição ou "tradução" do objeto refletido em imagem subjetiva, em ideal, ocorre; ao mesmo tempo, é também em atividade que a transição é alcançada do ideal em resultados objetivos da atividade, seus produtos, em material. Considerada deste ângulo, atividade é um processo de inter-tráfico entre polos opostos, sujeito e objeto.

Atividade é uma unidade não-aditiva da vida material, corpórea, do sujeito material. Em um sentido estreito, i.e., no plano psicológico, é uma unidade de vida, mediada pela reflexão mental, por uma imagem, cuja função real é orientar o sujeito no mundo objetivo.

Entretanto, não importam as condições e formas nas quais a atividade do homem procede, não importam quais estruturas adquire, não pode ser considerada como algo extraído de relações sociais, da vida da sociedade. Apesar de toda sua diversidade, todas as suas características especiais, a atividade do indivíduo humano é um sistema que obedece o sistema de relações da sociedade. Fora destas relações, a atividade humana não existe. Como ela existe é determinada pelas formas e meios da comunicação material e espiritual que são geradas pelo desenvolvimento da produção e não podem ser realizadas exceto na atividade de indivíduos específicos. É lógico que a atividade de todo indivíduo depende de seu lugar na sociedade, em suas condições de vida.

Isso precisa ser mencionado por causa dos persistentes esforços dos positivistas para opor o indivíduo à sociedade. A visão deles é que a sociedade provê somente um ambiente externo ao qual o homem precisa se adaptar para sobreviver, assim como um animal precisa se adaptar ao seu ambiente natural. A atividade do homem é moldada pelo sucesso ou fracasso de sua adaptação, mesmo que isso possa ser indireto (por exemplo, através da atitude tomada quanto a isso no grupo de referência). Mas a coisa principal é ignorada, que na sociedade o homem encontra não somente suas condições

\begin{tabular}{|c|c|c|c|c|}
\hline Qevista Dialectus & Ano 2 & n. 4 & Janeiro-Junho 2014 & p. $184-210$ \\
\hline
\end{tabular}


externas as quais ele deve adaptar sua atividade, mas também que aquelas mesmas condições sociais carregam em si mesmas os motivos e objetivos de sua atividade, as maneiras e meios de sua realização; em uma palavra, a sociedade produz a atividade humana. Isso não é dizer, naturalmente, que a atividade do indivíduo meramente copia e personifica os relacionamento da sociedade e sua cultura. Existem algumas ligações cruzadas muito complexas que excluem qualquer redução estrita de um ou de outro.

A característica básica constituinte da atividade é que ela tem um objeto. $\mathrm{Na}$ verdade, o próprio conceito de atividade (fazer, Tätigkeit) implica o conceito de objeto da atividade. A expressão "atividade sem objeto" não tem sentido algum. Atividade pode parecer não ter objeto, mas a investigação científica da atividade necessariamente demanda a descoberta de seu objeto. Além disso, o objeto da atividade aparece em duas formas: primeiro, em sua existência independente, comandando a atividade do sujeito, e segundo, como uma imagem mental do objeto, como o produto da "detecção" do sujeito de suas propriedades, que é efetuada pela atividade do sujeito e não pode ser efetuada de outra forma.

A natureza circular dos processos efetuando a interação do organismo com o ambiente tem sido geralmente reconhecida. Mas a coisa principal não é a estrutura circular enquanto tal, mas o fato de que a reflexão mental do mundo objetivo não é gerada diretamente pelas próprias influências externas, mas pelos processos através dos quais o sujeito chega ao contato prático com o mundo objetivo, e que, por conseguinte, necessariamente obedece suas propriedades, conexões e relações independentes. Isso significa que o agente aferente, que controla o processo da atividade, é primariamente o próprio objeto e, somente secundariamente, sua imagem como o produto subjetivo da atividade, que registra, estabiliza e carrega em si o conteúdo objetivo da atividade.

A forma geneticamente inicial e fundamental da atividade humana é atividade externa, atividade prática. Esta proposição tem implicações importantes, particularmente enquanto a psicologia, tradicionalmente, tem sempre estudado a atividade do pensamento e da imaginação, atos de memória, e assim por diante, desde que somente tal atividade interna era considerada psicológica. Psicologia, por conseguinte, ignorou o estudo da atividade sensorial, prática. E mesmo que a atividade externa figurou em alguma extensão na psicologia tradicional, o fez somente como uma expressão da atividade interna, a atividade da consciência.

$\mathrm{O}$ que exatamente temos em mente quando falamos de atividade? Vamos considerar o processo mais simples, o processo de perceber a resiliência de um objeto.

\begin{tabular}{|c|c|c|c|c|}
\hline Qevista Dialectus & Ano 2 & n. 4 & Janeiro-Junho 2014 & p. $184-210$ \\
\hline
\end{tabular}


Este é um processo aferente ou externo-motor, que pode buscar, ao realizar uma tarefa prática, por exemplo, a deformação do objeto. A imagem que surge ao longo do processo é, naturalmente, uma imagem mental e é, por conseguinte, indubitavelmente qualificada para o estudo psicológico. Mas, para entender a natureza desta imagem eu preciso estudar o processo que a gera, e no caso dado este é um processo externo e prático. Goste ou não, sou compelido a incluir o processo como parte do objeto de minha investigação psicológica.

Naturalmente, o mero estabelecimento da necessidade de uma investigação psicológica para estender à esfera da atividade objetiva externa não resolve o problema, porque pode ser assumido que, embora a atividade objetiva externa surge dentro de um intervalo de investigação psicológica, tal atividade desempenha um papel secundário, desde que é guiado por processos psicológicos internos que residem para além dele, e por essa razão a investigação psicológica, na verdade, não provê para a investigação desta atividade.

Este é um ponto a ser contado, mas somente se é assumido que a atividade externa é unilateralmente dependente da imagem que a controla, e que pode ou não ser reforçada pelo resultado de sua atividade. Mas não é assim. Atividade é obrigada a encontrar objetos que resistem ao homem que a desviam, mudam e enriquecem. Em outras palavras, é a atividade externa que destrava o círculo de processos mentais internos, que o abre para o mundo objetivo.

Será prontamente apreciado que a realidade com a qual o psicólogo está preocupado é essencialmente mais rica e mais complexa do que o simples esboço da forma como a imagem surge do contato com o objeto que acabamos de desenhar. Mas não importa quão remoto a realidade psicológica pode estar deste padrão rude, não importa quão profunda pode ser a metamorfose da atividade, atividade, sob todas as circunstâncias, permanecerá o materializador da vida de qualquer indivíduo dado.

A velha psicologia estava preocupada somente com processos internos, com a atividade da consciência. Além disso, por um longo tempo ignorou a questão da origem dessas atividades, i.e., suas verdadeiras naturezas. Hoje a proposição de que processos internos do pensamento são produzidos a partir do externo tem se tornado quase geralmente reconhecida. Em primeiro lugar, por exemplo, processos mentais internos tomam a forma de processos externos envolvendo objetos externos e, enquanto se tornam objetos internos, estes processos externos não mudam simplesmente sua forma, mas sofrem uma certa transformação, tornando-se mais gerais, contraídos, e assim por

\begin{tabular}{|c|c|c|c|c|}
\hline Qevista Dialectus & Ano 2 & n. 4 & Janeiro-Junho 2014 & p. $184-210$ \\
\hline
\end{tabular}


diante. Tudo isso é bem verdade, naturalmente, mas deve-se enfatizar que a atividade interna é atividade genuína, que retém a estrutura geral da atividade humana, não importa qual forma ela assume. Uma vez que reconhecemos a estrutura comum da atividade prática, externa, e atividade mental, interna, podemos entender a troca de elementos que constantemente ocorrem entre elas, podemos entender que certas ações mentais podem se tornar parte da estrutura da atividade material, prática, e, reciprocamente, operações externo-motoras podem servir para o desempenho da ação mental na estrutura da atividade puramente cognitiva. Na época atual, quando a integração e interpenetração destas formas de atividade humana estão ocorrendo diante dos nossos olhos, quando a oposição histórica entre elas tem sido constantemente e cada vez mais apagada, a significância da proposição é autoevidente.

Até agora falamos sobre atividade em geral, significado coletivo deste conceito. $\mathrm{Na}$ verdade, entretanto, temos que lidar com atividades específicas, concretas, cada uma das quais satisfaz uma necessidade definida do sujeito, é orientada em direção ao objeto desta necessidade, desaparece como um resultado de sua satisfação e é reproduzida talvez em condições diferentes e em relação a um objeto transformado.

A principal coisa que distingue uma atividade de outra reside na diferença entre seus objetos. É o objeto da atividade que a dota de certa orientação. Na terminologia que tenho usado o objeto da atividade é seu motivo. Naturalmente, ele pode ser tanto material quanto ideal; pode ser dado na percepção ou pode existir somente na imaginação, na mente.

Assim, atividades diferentes são distinguidas por seus motivos. O conceito de atividade é necessariamente ligado ao conceito de motivo. Não existe tal coisa como atividade sem um motivo; atividade "desmotivada" não é atividade que não possui motivo, mas atividade com um motivo subjetivamente e objetivamente escondido.

Os “componentes” básicos de atividades humanas separadas são as ações que as realizam. Consideramos ação o processo que corresponde à noção do resultado que deve ser atingido, isto é, o processo que obedece um objetivo consciente. Assim como o conceito de motivo está correlacionado com o conceito de atividade, o conceito de objeto é correlacionado com o de ação.

Historicamente, a aparência na atividade de processos de ação orientados a um objetivo foram o resultado do surgimento de uma sociedade baseada no trabalho. A atividade de pessoas trabalhando juntas é estimulada por seus produtos, que, em primeiro lugar, correspondem diretamente às necessidades de todos os participantes.

\begin{tabular}{|c|c|c|c|c|}
\hline Qevista Dialectus & Ano 2 & n. 4 & Janeiro-Junho 2014 & p. $184-210$ \\
\hline
\end{tabular}


Mas a mais simples divisão técnica de trabalho que surge no processo, necessariamente leva ao surgimento de resultados parciais, intermediários, que são obtidos pela participação individual na atividade de trabalho coletiva, mas que por elas mesmas não podem satisfazer a necessidade de cada participante. Essa necessidade é satisfeita não por resultados "intermediários", mas pela partilha do produto da atividade total que cada um recebe, graças aos relacionamentos entre os participantes que surge no processo de trabalho, isto é, as relações sociais.

Será facilmente entendido que este resultado "intermediário" que forma o padrão dos processos de trabalho do homem podem ser identificados por ele também subjetivamente, na forma de uma ideia. Isto é, na realidade, a definição do objetivo, que determina o método e caráter da atividade do indivíduo.

A identificação destes objetivos e a formação de atividades designadas para atingi-los leva a um tipo de divisão das funções que eram antes previamente unidas em seus motivos. Vamos assumir que a atividade de uma pessoa é estimulada por comida, este é seu motivo. Entretanto, para satisfazer a necessidade por comida, ele deve desempenhar ações que não são diretamente voltadas a obter comida. Quer ele mesmo use mais tarde o mecanismo que criou ou passe para outros participantes na caçada e receba parte do que foi apanhado ou morto, em ambos os casos seu motivo e objetivo não coincidem diretamente, exceto em casos particulares.

A separação das ações orientadas a um objetivo como componentes da atividade humana, naturalmente levantam a questão de suas relações internas. Como já dissemos, atividade não é um processo de adição. Consequentemente, ações não são coisas separadas que são incluídas na atividade. Atividade humana existe como ação ou uma corrente de ações. Se fossemos subtrair mentalmente da atividade as ações que a realizam, não sobraria nada da atividade. Isso pode ser expresso de outra forma. Quando consideramos o desdobramento de um processo específico - externo ou interno - a partir do ângulo do motivo, aparece como atividade humana, mas quando consideramos como um processo orientado a um objetivo, aparece como uma ação ou um sistema, uma corrente de ações.

Ao mesmo tempo, atividade e ação são ambas genuínas e, além disso, realidades não coincidentes, porque uma e a mesma ação pode realizar várias atividades, pode passar de uma atividade para outra, assim revelando sua relativa independência. Isso é devido ao fato de que uma dada ação pode ter motivos bastante diferentes, i.e., pode

\begin{tabular}{|c|c|c|c|c|}
\hline Qevista Dialectus & Ano 2 & n. 4 & Janeiro-Junho 2014 & p. $184-210$ \\
\hline
\end{tabular}


realizar atividades completamente diferentes. E um e o mesmo motivo pode gerar vários objetivos e assim várias ações.

Assim, no fluxo geral da atividade que forma a vida humana em sua mais alta manifestação (aquelas que são mediadas pela reflexão mental), análises identificam primeiramente atividades separadas, de acordo com o critério de diferença de seus motivos. Então os processos de ação obedecendo objetivos conscientes são identificados e, finalmente, as operações que são imediatamente dependentes das condições para sua realização de um objetivo específico.

Estas "unidades" de atividade humana formam sua macroestrutura. A análise pelas quais elas são identificadas não é um processo de desmembramento de atividade viva em elementos separados, mas de revelar as relações que caracterizam essa atividade. Tal sistema de análise simultânea exclui qualquer possibilidade de bifurcação da realidade que está sendo estudada, desde que lida não com processos diferentes, mas sim com planos diferentes de abstração. Assim, pode ser impossível à primeira vista, por exemplo, julgar se estamos lidando, em um caso dado, com ação ou com operação. Além disso, atividade é um sistema altamente dinâmico, que é caracterizado por transformações ocorrendo constantemente. Atividade pode perder o motivo que a evocou, no caso em que torna-se uma ação que percebe talvez um relacionamento bastante diferente do mundo, uma atividade diferente; reciprocamente, ação pode adquirir uma força motivacional independente e se tornar um tipo especial de atividade; e, finalmente, ação pode se transformar em um meio de alcançar um objetivo capaz de realizar ações diferentes.

O fato inquestionável permanece, de que a atividade do homem é regulada por imagens mentais da realidade. Qualquer coisa no mundo objetivo que se apresenta ao homem, como os motivos, objetivos e condições de sua atividade, deve, de uma forma ou de outra, ser percebida, entendida, retida e reproduzida por sua memória; isso também se aplica aos processos de sua atividade, e a ele mesmo, seus estados e características individuais.

Assim, segue que a consciência do homem em sua imediaticidade é o retrato do mundo que se desdobra para ele, um retrato no qual ele próprio, suas ações e estados, estão incluídos.

Para a pessoa não iniciada, a existência deste retrato subjetivo não vai, naturalmente, dar origem a qualquer problema teórico; ele é confrontado com o mundo, não o mundo e um retrato do mundo. Este realismo espontâneo contém um elemento

\begin{tabular}{|c|c|c|c|c|}
\hline Qevista Dialectus & Ano 2 & n. 4 & Janeiro-Junho 2014 & p. $184-210$ \\
\hline
\end{tabular}


real, até mesmo ingênuo, de verdade. É uma questão diferente quando equacionamos reflexão mental com consciência; isso não é mais que uma ilusão de nossa introspecção. Essa ilusão surge de um aparente alcance da consciência. Quando nos perguntamos se estamos cientes deste ou daquele fenômeno, nos damos a tarefa de tornarmos cientes disso e, naturalmente, na prática completamos instantaneamente essa tarefa. Foi necessário elaborar uma técnica especial de usar um taquistoscópio ${ }^{3}$ para separar experimentalmente o campo da percepção do campo da consciência.

Por outro lado, certos fatos bem conhecidos, que podem ser facilmente reproduzidos em condições laboratoriais, nos mostram que o homem é capaz de complexos processos adaptativos em relação a objetos do ambiente, sem estar consciente de suas imagens; ele negocia obstáculos e até mesmo manipula coisas sem realmente "vê-las".

É uma questão diferente se ele deve fazer ou mudar uma coisa de acordo com um padrão ou representar, retratar algum conteúdo objetivo. Quando eu moldo, vamos dizer, um pentágono a partir do arame, ou desenho ele, eu devo, necessariamente, comparar a noção que tenho dele com as condições objetivas, com os estágios de sua realização no produto; devo medir internamente um contra o outro. Tais medições ou acessórios demandam que minha noção deveria para mim parecer ser, por assim dizer, no mesmo plano do mundo objetivo e ainda assim não fundir com ele. Isso é particularmente evidente nos casos quando estamos lidando com problemas que precisam ser resolvidos por desempenhar preliminarmente "em nossas cabeças" o mútuo deslocamento espacial de imagens de objetos que precisam ser correlacionados. Tal é, por exemplo, o tipo de problema que demanda a virada mental de uma figura inscrita em outra figura.

Historicamente, a necessidade por tal "apresentação" da imagem mental para o sujeito surge somente durante a transição da atividade adaptativa dos animais para a atividade laboral, produtiva, que é peculiar ao homem. O produto ao qual a atividade é agora direcionada não existe ainda. Assim, ela pode regular a atividade somente se é apresentada ao sujeito de tal forma que o permita compará-la com o material original (objeto do trabalho) e com suas transformações intermediárias. Ainda mais, a imagem mental do produto como um objetivo deve existir para o sujeito de tal maneira que ele pode agir com esta imagem - modificá-la de acordo com as condições à disposição.

${ }^{3}$ [Aparelho destinado a examinar a rapidez da percepção visual e a explorar o seu campo. - M.S.]

\begin{tabular}{|c|c|c|c|c|}
\hline Qevista Dialectus & Ano 2 & n. 4 & Janeiro-Junho 2014 & p. $184-210$ \\
\hline
\end{tabular}


Tais imagens são imagens conscientes, noções conscientes, ou, em outras palavras, os fenômenos da consciência.

Nela mesma a necessidade por fenômenos da consciência surgirem na cabeça do homem não nos diz qualquer coisa sobre o processo pelo qual eles surgem. Entretanto, nos dá um alvo claro para nosso estudo destes processos. O ponto é que, em termos do padrão díade "objeto-sujeito" tradicional, a existência de consciência no sujeito é aceita sem quaisquer explicações, a não ser que contemos as interpretações que assumem a existência em nossas cabeças de algum tipo de observador contemplando os retratos tecidos por processos cerebrais.

O método de análise científica da geração e funcionamento da consciência humana - social e individual - foi descoberto por Marx. O resultado foi que o estudo da consciência mudou seu alvo, da subjetividade do indivíduo para os sistemas sociais de atividade.

É autoevidente que a explicação da natureza da consciência reside nas características peculiares da atividade humana que criam a necessidade disso - no caráter produtivo, objetivo, da atividade. Atividade laboral está impressa, perpetuada em seu produto. Lá ocorre, nas palavras de Marx, uma transição da atividade em uma propriedade estática. Essa transição é o processo de encarnação material do conteúdo objetivo da atividade, que agora se apresenta para o sujeito, isso quer dizer, surge diante dele na forma de uma imagem do objeto percebido.

Em outras palavras, uma aproximação grosseira da geração de consciência pode ser esboçada assim: a representação controlando a atividade, quando encarnada em um objeto, adquire sua segunda, "objetivada", existência, que pode ser sensorialmente percebida; como um resultado, o sujeito, por assim dizer, vê a si mesmo representado no mundo externo. Quando tiver sido assim duplicado, é entendido conscientemente. Este padrão não é válido, entretanto. Ele nos leva de volta ao ponto de vista prévio, particularmente idealístico, subjetivamente empírico, que enfatiza acima de tudo o fato de que essa transição particular é pressuposto na consciência, no sujeito tendo certas representações, intenções, planos mentais, padrões ou "modelos", isso quer dizer, fenômenos mentais objetivados na atividade e em seus produtos. Já a própria atividade do sujeito, é controlada pela consciência e desempenha em relação ao seu conteúdo somente uma função de transferência e a função de seu "reforço e não-reforço".

Mas a questão principal não é indicar o papel controlador, ativo, da consciência. O problema principal reside em entender a consciência como um produto subjetivo,

\begin{tabular}{|c|c|c|c|c|}
\hline Qevista Dialectus & Ano 2 & n. 4 & Janeiro-Junho 2014 & p. $184-210$ \\
\hline
\end{tabular}


como uma manifestação em uma forma diferente de relações essencialmente sociais que são materializadas pela atividade do homem no mundo objetivo. Atividade não é, de maneira alguma, simplesmente aquela que expressa e o veículo da imagem mental objetivada em seu produto. O produto grava, perpetua não a imagem, mas a atividade, o conteúdo objetivo que ele objetivamente carrega dentro de si.

As transições sujeito-atividade-objeto formam um tipo de movimento circular, assim pode parecer insignificante quais de seus elementos ou momentos são tomados como o inicial. Mas isso não é, de maneira alguma, movimento em um círculo fechado. $\mathrm{O}$ círculo abre, e abre especificamente na própria atividade prática sensorial. Entrando em contato direto com a realidade objetiva e submetendo a ela, a atividade é modificada e enriquecida; e é nessa forma enriquecida que ela é cristalizada no produto. Atividade materializada é mais rica, mais verdadeira do que a consciência a antecipa. Além disso, para a consciência do sujeito as contribuições feitas por sua atividade permanecem escondidas. Assim vem que a consciência pode aparecer como sendo a base da atividade.

Vamos colocar de uma maneira diferente. A reflexão dos produtos da atividade objetiva que materializa as conexões e relacionamentos entre indivíduos sociais aparece para ele como sendo fenômenos das conexões e relacionamentos objetivos acima mencionados, não em uma forma clara e óbvia, mas em uma forma suprassumida, escondida do sujeito. Ao mesmo tempo, os fenômenos da consciência constituem um elemento real no movimento da atividade. É isso que os fazem essenciais, isso quer dizer, a imagem consciente desempenha a função da medida ideal, que é materializada na atividade.

Essa abordagem da consciência faz uma diferença radical na forma com a qual o problema da correlação da imagem subjetiva e do objeto externo é colocado. Ela se livra da mistificação deste problema, que o postulado da imediaticidade cria. Se alguém procede a partir da assunção de que influências externas nos evocam imediatamente, diretamente, em nosso cérebro, uma imagem subjetiva, esse alguém é imediatamente confrontado com a questão de como acontece dessa imagem parecer existir fora de nós, fora de nossa subjetividade, nas coordenadas do mundo externo.

Em termos do postulado da imediaticidade, esta questão pode ser respondida somente ao assumir um processo de projeção secundária, por assim dizer, da imagem mental no mundo externo. A fraqueza teórica de tal assunção é óbvia. Além disso, está claramente em contradição com os fatos, que testemunham que a imagem mental é

\begin{tabular}{|c|c|c|c|c|}
\hline Qevista Dialectus & Ano 2 & n. 4 & Janeiro-Junho 2014 & p. $184-210$ \\
\hline
\end{tabular}


desde o início "relacionada" com a realidade, que é externa ao cérebro do sujeito, e que não é projetada no mundo externo, mas sim extraída, escavada dele. Naturalmente, quando falo "escavada", isso não é mais que uma metáfora. Ela, entretanto, expressa um processo real que pode ser pesquisado cientificamente, o processo da assimilação do sujeito do mundo objetivo em sua forma ideal, a forma de sua reflexão consciente.

Este processo surge, originalmente, no sistema de relações objetivas nas quais ocorre a transição do conteúdo objetivo da atividade em seu produto. Mas, para este processo ser percebido, não é suficiente que o produto da atividade, tendo absorvido essa atividade, deve se apresentar ao sujeito como suas propriedades materiais; uma transformação deve ocorrer que o permita emergir como algo que o sujeito está ciente, isso quer dizer, em uma forma ideal. Essa transformação é afetada por meios da linguagem, que é o produto e meio de comunicação de pessoas ocorrendo na produção. A linguagem carrega em seus significados (conceitos) um certo conteúdo objetivo, mas um conteúdo completamente liberado de sua materialidade.

Assim, a consciência individual, como uma forma especificamente humana de reflexão subjetiva da realidade objetiva, pode ser entendida somente como um produto daquelas relações e mediações que surgem ao longo do estabelecimento e desenvolvimento da sociedade. Fora do sistema dessas relações (e fora da consciência social) a existência da mentalidade individual, a psique, na forma de consciência é impossível, especialmente quando até mesmo o estudo dos fenômenos da consciência em termos de atividade humana nos permitem entende-los somente na condição de que a própria atividade do homem é reconhecida como um processo incluído no sistema de relações, um processo que percebe seu ser social, que é o meio de sua existência também como uma criatura corpórea, natural.

Naturalmente, as condições e relações acima mencionadas que geram a consciência humana caracterizam-na somente nos estágios iniciais. Subsequentemente, enquanto a produção material e comunicação se desenvolvem, a consciência das pessoas é liberada da conexão direta com suas atividades laborais práticas imediatas e a instrumentalização da linguagem. O alcance do que foi criado constantemente aumenta, assim a consciência do homem torna-se a forma universal, apesar de não a única, de reflexão mental. Ao longo deste processo ela sofre certas mudanças radicais.

Para começar, a consciência existe somente na forma de uma imagem mental revelando ao sujeito o mundo ao redor. Atividade, por outro lado, ainda permanece prática, externa. Em um estágio mais adiante a atividade também se torna um objeto da

\begin{tabular}{|c|c|c|c|c|}
\hline Qevista Dialectus & Ano 2 & n. 4 & Janeiro-Junho 2014 & p. $184-210$ \\
\hline
\end{tabular}


consciência; o homem se torna ciente das ações de outros homens e, através deles, de suas próprias ações. Eles são agora comunicáveis por gestos ou discurso oral. Essa é a pré-condição para a geração de ações e operações internas que ocorrem na mente, no "plano da consciência”. Imagem-consciência torna-se também atividade-consciência. É nesta plenitude que a consciência começa a parecer emancipada da atividade sensorial prática, externa, e, ainda mais, parece controla-la.

Outra mudança fundamental que a consciência sofre ao longo do desenvolvimento histórico consiste na destruição da coesão original da consciência do trabalho coletivo e aquela de seus membros individuais. Isso ocorre porque o alcance da consciência aumenta, tomando fenômenos que pertencem à esfera das relações individuais, constituindo algo especial na vida de cada um deles. Além disso, a divisão de classe da sociedade coloca as pessoas em relações opostas, desiguais, quanto aos meios de produção e o produto social, consequentemente suas consciências experimentam a influência desta inequidade, esta oposição. Ao mesmo tempo, noções ideológicas são desenvolvidas e entram no processo pelo quais indivíduos específicos tornam-se cientes de suas relações reais de vida.

Assim surge um retrato complexo de conexões internas, entrelaçamento e intertráfico, gerado pelo desenvolvimento de contradições internas, que, em forma abstrata, torna-se aparente na análise das relações mais simples, caracterizando o sistema de atividade humana. À primeira vista, a imersão da pesquisa neste intricado retrato pode parecer desviar da tarefa do estudo psicológico específico da consciência, e levar para a substituição da sociologia pela psicologia. Mas este não é o caso. Pelo contrário, as características psicológicas da consciência individual podem ser entendidas somente através de suas conexões com as relações sociais nas quais o indivíduo torna-se envolvido.

Nos fenômenos da consciência descobrimos, acima de tudo, seus tecidos sensoriais. É este tecido que forma a composição sensorial da imagem específica da realidade - na verdade percebida ou surgindo na memória, referida ao futuro ou talvez somente imaginada. Estas imagens podem ser distinguidas por suas modalidades, seus tons sensoriais, graus de clareza, mais ou menor persistência, e assim por diante.

A função especial das imagens sensoriais da consciência é que elas adicionam realidade ao retrato consciente do mundo revelado ao sujeito. Em outras palavras, é graças ao conteúdo sensorial da consciência que o mundo é visto pelo sujeito como existindo não em sua consciência, mas fora dela, como o "campo" objetivo e objeto de

\begin{tabular}{|c|c|c|c|c|}
\hline Qevista Dialectus & Ano 2 & n. 4 & Janeiro-Junho 2014 & p. $184-210$ \\
\hline
\end{tabular}


sua atividade. Esta asserção pode parecer paradoxal porque o estudo dos fenômenos sensoriais tem, desde tempos imemoriais, procedido de posições que levam, ao contrário, à ideia de suas "subjetividades puras", suas "naturezas hieróglifas". Da mesma maneira, o conteúdo sensorial das imagens não foi visto como algo afetando "a conexão imediata entre consciência e o mundo externo", mas sim como uma barreira entre eles.

No período pós-Helmholtz ${ }^{4}$, o estudo experimental dos processos de percepção alcançaram grande sucesso. A psicologia da percepção é agora inundada com fatos de hipóteses individuais. Mas a coisa surpreendente é que, apesar desse sucesso, a posição teórica de Helmholtz permanece inabalada. Reconhecidamente, em muitos estudos psicológicos está presente de maneira invisível, como plano de fundo, por assim dizer. Somente alguns psicólogos discutem ela seriamente e abertamente, como Richard L. Gregory, por exemplo, o autor do que é provavelmente o mais absorvente dos livros modernos sobre percepção visual ${ }^{5}$.

A robustez da posição de Helmholtz reside no fato de que, ao estudar a fisiologia da visão, ele entendeu a impossibilidade de inferir as imagens dos objetos diretamente das sensações, de identifica-las com os padrões desenhados pelos raios de luz na retina do olho. Em termos de estrutura conceitual da ciência natural nos dias de hoje, a solução para o problema proposta por Helmholtz, sua proposição de que o trabalho dos órgãos sensoriais é necessariamente suplementado pelo trabalho do cérebro, que constrói a partir de dicas sensoriais suas hipóteses ("inferências") sobre a realidade objetiva, era a única possível.

O ponto é que as imagens objetivas da consciência foram pensadas como fenômenos mentais dependendo de outros fenômenos para suas causas externas. Em outras palavras, a análise procedeu do plano da abstração dual, que foi expressa, por um lado, na exclusão dos processos sensórios a partir do sistema da atividade do sujeito e, por outro lado, na exclusão das imagens sensoriais a partir do sistema da consciência humana. A ideia do objeto do conhecimento científico como um sistema não foi elaborado adequadamente.

Em contraste a esta abordagem, que considera os fenômenos em isolamento um do outro, o sistema de análise da consciência necessita de que os "elementos

\footnotetext{
${ }^{4}$ [Hermann von Helmholtz $(1821$ - 1894) foi um cientista alemão que, na fisiologia e psicologia estudou matematicamente o olho, desenvolveu teorias da visão, ideias sobre a percepção visual do espaço, pesquisas sobre a visão colorida, sobre a sensação do tom e percepção do som. - M.S.]

${ }_{5}^{5}$ Richard Langton Gregory, The Intelligent Eye, London 1970.
}

\begin{tabular}{|c|c|c|c|c|}
\hline Qevista Dialectus & Ano 2 & n. 4 & Janeiro-Junho 2014 & p. $184-210$ \\
\hline
\end{tabular}


formativos" da consciência sejam estudados em seus relacionamentos internos, gerados pelo desenvolvimento das formas de conexão que o sujeito tem com a realidade e, consequentemente, primariamente a partir do ponto de vista da função que cada um deles cumpre nos processos de apresentar o retrato do mundo para o sujeito. Os dados sensoriais incorporados no sistema de consciência não revelam suas funções diretamente; subjetivamente esta função é expressa somente indiretamente, em um nãodiferenciado "sentido da realidade". Entretanto, se revela imediatamente tão logo exista qualquer interferência ou distorção na recepção de influências externas.

A natureza profunda das imagens sensoriais mentais residem em suas objetividades, no fato de que elas são geradas no processo da atividade, formando a conexão prática entre o sujeito e o mundo objetivo externo. Não importa quão complexas essas relações e as formas de atividade que as realizam se tornam, as imagens sensoriais retêm suas referências objetivas iniciais.

Naturalmente, quando comparamos com a imensa riqueza de resultados cognitivos da atividade humana desenvolvida, as contribuições feitas diretamente por nossas percepções sensoriais, nossa sensibilidade, a primeira coisa que nos impressiona é quão limitadas são, quase desprezíveis. Ainda mais, descobrimos que as percepções sensoriais constantemente contradizem nossa visão mental. Disso surge a ideia de que as percepções sensoriais provêm somente o empurrão que coloca nossas habilidades cognitivas em movimento, e que as imagens dos objetos são geradas por operações internas do pensamento, inconsciente ou consciente; em outras palavras, que não deveríamos perceber o mundo objetivo se não o concebêssemos. Mas, como conceberíamos este mundo se ele, em primeiro lugar, não se revelar para nós em sua objetividade sensorialmente dada?

Imagens sensoriais são uma forma universal de reflexão mental gerada pela atividade objetiva do sujeito. Mas no homem imagens adquirem uma nova qualidade, nomeadamente, seus significados ou valores. Valores são assim os "elementos formativos" mais importantes da consciência humana.

Como sabemos, uma lesão nos sistemas sensórios principais - visão e audição não destrói a consciência. Até mesmo surdo, mudo e cego, crianças que dominaram as operações especificamente humanas de atividade e linguagem objetivas (o que só pode ser feito através de ensino especial, naturalmente), adquirem uma consciência normal, diferente da consciência normal de pessoas que podem ver e ouvir, somente em sua textura sensorial, que é extremamente pobre. É uma questão diferente quando, por uma

\begin{tabular}{|c|c|c|c|c|}
\hline Qevista Dialectus & Ano 2 & n. 4 & Janeiro-Junho 2014 & p. $184-210$ \\
\hline
\end{tabular}


razão ou outra, esta "hominização" da atividade e relações não ocorre. Neste caso, apesar do fato de que a esfera sensório-motora possa estar inteiramente intacta, a consciência não surge.

Assim, significados refratam o mundo na consciência do homem. O veículo do significado é a linguagem, mas linguagem não é o demiurgo do significado. Oculto atrás dos significados linguísticos (valores) estão modos socialmente desenvolvidos de ação (operações), no processo pelo qual pessoas mudam e conhecem a realidade objetiva. Em outras palavras, significados são a forma ideal materializada e linguisticamente transmutada de existência do mundo objetivo, suas propriedades, conexões e relações reveladas pela prática social agregada. Significados neles mesmos, isso quer dizer, em abstração de seus funcionamentos na consciência individual, são tão "psicológicos" quanto a realidade socialmente conhecida que reside para além deles.

Significados são estudados - em linguística, semiótica e lógica. Ao mesmo tempo, como um dos "elementos formativos" da consciência individual, eles são obrigados a entrar no alcance dos problemas da filosofia. A principal dificuldade do problema filosófico do significado reside no fato de que ele reproduz todas as contradições envolvidas no problema mais amplo da correlação entre o lógico e o psicológico no pensamento, entre a lógica e a psicologia dos conceitos.

Uma solução para este problema, oferecida pela psicologia empírica-subjetiva, é que conceitos (ou significados verbais) são um produto psicológico, o produto da associação e generalização de impressões na consciência do sujeito individual, os resultados que tornam-se ligados às palavras. Este ponto de vista, como sabemos, encontrou expressão não somente na psicologia, mas também em concepções que reduzem lógica a psicologia.

Outra alternativa é reconhecer que conceitos e operações com conceitos são controlados por leis lógicas objetivas, que a psicologia está preocupada somente com os desvios destas leis para serem observados no pensamento primitivo, em condições de patologia ou grande stress emocional, e que é tarefa da psicologia estudar o desenvolvimento ontogenético dos conceitos e pensamento. Realmente, o estudo deste processo predomina na psicologia do pensamento. É suficiente mencionar os trabalhos de Piaget, Vigotski e os numerosos estudos soviéticos e estrangeiros da psicologia do ensino.

Estudos de como crianças formam conceitos e operações (mentais) lógicas deram uma grande contribuição para este campo. Foi mostrado que a formação de

\begin{tabular}{|c|c|c|c|c|}
\hline Qevista Dialectus & Ano 2 & n. 4 & Janeiro-Junho 2014 & p. $184-210$ \\
\hline
\end{tabular}


conceitos no cérebro da criança não segue o padrão de formação de imagens genéricas sensoriais. Tais conceitos são o resultado de um processo de assimilação do "não original", significados historicamente desenvolvidos, e este processo ocorre na atividade da criança durante seu relacionamento com as pessoas ao seu redor. Ao aprender a desempenhar certas ações, a criança domina as operações correspondentes, que são, na verdade, uma forma idealizada, comprimida, representada no significado.

É lógico que, inicialmente, o processo de assimilação de significados ocorre na atividade externa da criança com objetos materiais e no relacionamento prático que isso requer. Nos primeiros estágios, a criança assimila certos significados objetivos específicos, diretamente referenciáveis; subsequentemente, ela também domina certas operações lógicas, mas também em suas formas exteriorizadas externas - caso contrário elas não seriam comunicáveis. Enquanto são interiorizadas, elas formam significados ou conceitos abstratos, e seus movimentos constituem atividade mental interna, atividade "no plano da consciência".

Consciência como uma forma de reflexão mental, entretanto, não pode ser reduzida ao funcionamento de significados externamente assimilados, que então desdobram e controlam a atividade interna e externa do sujeito. Significados e operações envoltas neles e não neles mesmos, isso quer dizer, em suas abstrações a partir das relações internas do sistema de atividade e consciência, de qualquer parte do tema da psicologia. Eles assim o fazem somente quando são considerados dentro dessas relações, nas dinâmicas de seus sistemas.

Isso deriva da própria natureza dos fenômenos mentais. Como dissemos, reflexão mental ocorre devido à bifurcação dos processos vitais do sujeito em processos que realizam suas relações bióticas diretas e os processos "de sinalização" que os mediam. O desenvolvimento das relações internas geradas por esta divisão é expresso no desenvolvimento da estrutura da atividade e, nesta base, também no desenvolvimento das formas de reflexão mental. Subsequentemente, no nível humano, estas formas estão tão alteradas que, enquanto elas se tornam estabelecidas na linguagem (ou linguagens), elas adquirem uma existência quase independente como fenômenos ideais objetivos.

Além disso, elas são constantemente reproduzidas pelos processos que ocorrem nas cabeças dos indivíduos específicos, e é isso que constitui o "mecanismo" interno de suas transmissões de geração para geração, e uma condição de seus enriquecimentos por meios das contribuições individuais.

\begin{tabular}{|l|l|l|l|l|}
\hline Qevista Dialectus & Ano 2 & n. 4 & Janeiro-Junho 2014 & p. 184-210 \\
\hline
\end{tabular}


Neste ponto chegamos ao problema que é sempre uma pedra no caminho da análise da consciência. Este é o problema da natureza específica do funcionamento do conhecimento, conceitos, modelos conceituais etc., no sistema de relações sociais, na consciência social, por um lado, e, por outro lado, na atividade do indivíduo que percebe suas relações sociais, na consciência individual.

Este problema inevitavelmente confronta qualquer análise que reconhece as limitações da ideia de que significados na consciência individual são somente mais ou menos projeções completas dos significados "supra-individuais" existentes em uma dada sociedade. O problema não é, de forma alguma, removido por referências ao fato de que significados são refratados por características específicas do indivíduo, sua experiência anterior, a natureza única de seus princípios pessoais, índole, e assim por diante.

Este problema surge a partir da dualidade real de existência dos significados para o sujeito. Esta dualidade reside no fato de que os significados se apresentam eles mesmos para o sujeito, tanto em suas existências independentes - como objetos de sua consciência - e ao mesmo tempo como os meios e "mecanismo" de compreensão, isto é, quando funcionando nos processos que apresentam a realidade objetiva para o sujeito. Nessa função, os significados necessariamente entram em um relacionamento interno ligando-os com outros "elementos formativos" da consciência individual; é somente nestes relacionamentos sistêmicos internos que eles adquirem características psicológicas.

Vamos colocar isso de uma forma diferente. Quando os produtos da prática sócio-histórica, idealizada em significados, se torna parte da reflexão mental do mundo pelo sujeito individual, eles adquirem novas qualidades sistêmicas. A maior dificuldade aqui é que significados possuem uma vida dupla. Eles são produzidos pela sociedade e têm suas histórias no desenvolvimento da linguagem, na história do desenvolvimento de formas de consciência social; eles expressam o movimento da ciência e seus meios de conhecimento, e também as noções ideológicas da sociedade - religioso, filosófico e político. Nesta existência objetiva deles, significados obedecem as leis sócio-históricas e, ao mesmo tempo, a lógica interna de seus desenvolvimentos.

Entretanto, apesar de toda riqueza inexaurível, toda a diversidade desta vida de significados (é disso que todas as ciências tratam), permanece escondida dentro dela outra vida e outro tipo de movimento - seus funcionamentos nos processos de atividade e consciência de indivíduos específicos, mesmo que eles só possam existir nestes

\begin{tabular}{|c|c|c|c|c|}
\hline Qevista Dialectus & Ano 2 & n. 4 & Janeiro-Junho 2014 & p. $184-210$ \\
\hline
\end{tabular}


processos. Nessa segunda vida, significados são individualizados e "subjetivizados" somente no sentido de que seus movimentos no sistema de relações sociais não estão contidos diretamente neles; eles entram em outro sistema de relacionamentos, outro movimento. Mas a coisa notável é que, ao fazê-lo, eles não perdem suas naturezas sócio-históricas, suas objetividades.

Um aspecto do movimento dos significados na consciência dos indivíduos específicos reside em seus "retornos" à objetividade sensorial do mundo que foi mencionado acima. Enquanto em suas abstrações, em suas "supra-individualidades", significados são indiferentes às formas de sensorialidade nas quais o mundo é revelado ao indivíduo específico (pode ser dito que neles mesmos, significados são desprovidos de sensorialidade), seus funcionamentos na percepção do sujeito do verdadeiro relacionamento na vida necessariamente pressupõe suas referências às influências sensoriais. Naturalmente, a referência sensória-objetiva que significados possuem na consciência do sujeito não precisa ser necessariamente direta; ela pode ser percebida através de todos os tipos de intricadas correntes de operações mentais, envolvidas nelas, particularmente quando esses significados refletem uma realidade que aparece somente em suas formas oblíquas, remotas. Mas, em casos normais, essa referência sempre existe, e desaparece somente nos produtos de seus movimentos, em suas exteriorizações.

O outro lado do movimento dos significados no sistema da consciência individual reside em suas subjetividades especiais, que são expressas na parcialidade, no viés que eles adquirem. Este lado é revelado, entretanto, somente por análises das relações internas que ligam significados com ainda outro "elemento formativo" da consciência - o significado pessoal.

Vamos considerar esta questão um pouco mais de perto. A psicologia empírica tem descrito a subjetividade, a parcialidade da consciência humana, por séculos. Ela tem observado em atenção seletiva, na coloração emocional de ideais, na dependência dos processos cognitivos sobre necessidades e inclinações. Foi Leibniz em sua época que expressou esta dependência em seu bem conhecido aforismo do efeito de que "se a geometria foi o oposto de nossas paixões e interesses como é a moralidade, nós deveríamos contestar seus argumentos e violar seus princípios apesar de todas as provas de Euclides e Arquimedes [...]"

\footnotetext{
${ }^{6}$ Gottfried Wilhelm von Leibniz, Neue Abhandlungen über den menschlichen Verstand, Leipzig 1915.
}

\begin{tabular}{|l|l|l|l|l|}
\hline Qevista Dialectus & Ano 2 & n. 4 & Janeiro-Junho 2014 & p. 184-210 \\
\hline
\end{tabular}


A dificuldade reside na explicação psicológica da parcialidade da cognição. Os fenômenos da consciência parecem ter uma determinação dual - externa e interna. Eles estão conformemente interpretados como pertencentes a duas esferas mentais diferentes, a esfera dos processos cognitivos e a esfera das necessidades, de afeição. O problema de correlacionar estas duas esferas, seja se foi resolvido no espírito das concepções racionalistas ou de profundos processos psicológicos, foi invariavelmente interpretado a partir de uma posição antropológica, uma posição que assumiu a interação dos fatores ou forças essencialmente heterogêneos.

Entretanto, a verdadeira natureza da aparente dualidade dos fenômenos da consciência individual reside não em suas obediências a estes fatores independentes, mas nas características específicas da estrutura interna da própria atividade humana.

Como já dissemos, a consciência deve sua origem à identificação no decurso do trabalho de ações cujos resultados cognitivos são abstraídos do todo vivo da atividade humana, e idealizados na forma de significados linguísticos. Enquanto eles são transmitidos, eles se tornam parte da consciência dos indivíduos. Isso não os priva de suas qualidades abstratas, porque eles continuam a implicar os significados, condições objetivas e resultados de ações, independentemente da motivação subjetiva da atividade das pessoas nas quais eles foram formados. Nos estágios iniciais, quando as pessoas participando do trabalho coletivo ainda possuíam motivos comuns, significados como fenômenos da consciência social e como fenômenos da consciência individual correspondiam diretamente uma a outra. Mas este relacionamento não dura em um desenvolvimento adicional. Ele desintegra junto com a desintegração dos relacionamentos originais entre indivíduos e as condições materiais e meios de produção, junto com o surgimento da divisão social do trabalho e propriedade privada ${ }^{7}$. O resultado é que significados socialmente desenvolvidos começam a viver um tipo de vida dupla na consciência dos indivíduos. Ainda outro relacionamento, outro movimento de significados no sistema de consciências individuais é trazido à existência.

Este relacionamento interno específico se manifesta nos fatos psicológicos mais simples. Por exemplo, todas as crianças alunas mais velhas sabem o significado de uma nota de prova e as consequências que isso tem. Não obstante, uma nota pode aparecer na consciência de cada pupilo individual de maneiras essencialmente diferentes; ela

\footnotetext{
${ }^{7}$ Karl Marx, Contribuição à Crítica da Economia Política, 1859.
}

\begin{tabular}{|l|l|l|l|l|}
\hline Qevista Dialectus & Ano 2 & n. 4 & Janeiro-Junho 2014 & p. 184-210 \\
\hline
\end{tabular}


pode, por exemplo, aparecer como um passo em direção (ou obstáculo) ao caminho de sua profissão escolhida, ou como um meio de se afirmar aos olhos das pessoas a sua volta, ou talvez de alguma outra maneira. É isso que compele a psicologia a distinguir entre o significado objetivo consciente e seu significado para o sujeito, ou o que prefiro chamar de "significado pessoal". Em outras palavras, uma nota de prova pode adquirir significados pessoais diferentes na consciência de pupilos diferentes.

Embora esta interpretação do relacionamento entre os conceitos do significado e significado pessoal tem repetidamente sido explicada, é ainda mal interpretada bastante frequentemente. Pareceria ser necessário, portanto, retornar à análise do conceito de significado pessoal mais uma vez. Primeiro de tudo, algumas poucas palavras sobre as condições objetivas que levam a diferenciação de significados e significados pessoais na consciência individual. Em seu bem conhecido artigo criticando Adolf Wagner ${ }^{8}$, Marx observa que os objetos do mundo externo conhecidos pelo homem eram originalmente designados como os meios de satisfazer suas necessidades, isso quer dizer que eles eram para ele "bens". "[...] Eles dotam um objeto com o caráter de utilidade embora utilidade fosse intrínseca ao próprio objeto", escreve Marx ${ }^{9}$. Este pensamento põe em relevo uma característica muito importante da consciência nos estágios iniciais do desenvolvimento, nomeadamente o fato de que objetos são refletidos na linguagem e consciência como parte de um todo único, junto com as necessidades humanas que eles concretizam ou "reificam". Esta unidade é, entretanto, subsequentemente destruída. A inevitabilidade de sua destruição está implicada nas contradições objetivas da produção de mercadoria, que gera uma contradição entre o trabalho concreto e abstrato e leva à alienação da atividade humana.

Não iremos entrar nas características específicas que distinguem as várias formações sócio-econômicas a este respeito. Para a teoria geral da consciência individual, a coisa principal é que a atividade de indivíduos específicos está sempre "confinada" (insére) nas formas atuais de manifestação destes opostos objetivos (por exemplo, trabalho concreto e abstrato), que encontram suas expressões fenomênicas, indiretas, na consciência dos indivíduos, em seu movimento interno específico.

Historicamente, a atividade do homem não muda sua estrutura geral, sua "macroestrutura". A cada estágio do desenvolvimento histórico, ela é percebida pelas ações conscientes nas quais os objetivos tornam-se produtos objetivos, e obedecem os

\footnotetext{
${ }^{8}$ [Karl Marx, Glosas marginais ao "Tratado de Economia Politica” de Adolfo Wagner, 1881 - M.S.]

${ }^{9}$ Karl Marx, Capital I, MECW vol. 35, p. 46.
}

\begin{tabular}{|l|l|l|l|l|}
\hline Qevista Dialectus & Ano 2 & n. 4 & Janeiro-Junho 2014 & p. 184-210 \\
\hline
\end{tabular}


motivos pelos quais foram estimuladas. O que muda radicalmente é o caráter dos relacionamentos que conectam os objetos e motivos da atividade. Estes relacionamentos são psicologicamente decisivos. O ponto é que para o próprio sujeito a compreensão e realização de objetivos concretos, seu domínio de certos modos e operações de ação é uma forma de afirmar, preencher sua vida, satisfazendo e desenvolvendo suas necessidades materiais e espirituais, que estão reificadas e transformadas em motivos de sua atividade. Não faz diferença se o sujeito está consciente ou inconsciente de seus motivos, se eles declaram suas existências na forma de interesse, desejo ou paixão. Suas funções, consideradas a partir da posição da consciência, é para "avaliar", por assim dizer, o significado vital para o sujeito das circunstâncias objetivas e suas ações nessas circunstâncias, em outras palavras, para dotá-las de significado pessoal, o que não coincide diretamente com seus significados objetivos entendidos. Sob certas condições, a discrepância entre significados pessoais e significados objetivos na consciência individual pode equivaler a alienação ou até mesmo oposição diametral.

Em uma sociedade baseada na produção de mercadorias, esta alienação é obrigada a surgir; além disso, surge entre pessoas nos dois extremos da escala social. $\mathrm{O}$ trabalhador empregado, naturalmente, está ciente do produto que ele produz; em outras palavras, ele está ciente de seu significado objetivo (Bedeutung) ao menos na extensão necessária para ele ser capaz de desempenhar suas funções laborais de forma racional. Mas isso não é o mesmo que o significado pessoal (Sinn) de seu trabalho, que reside nos salários pelos quais ele está trabalhando. "As doze horas de trabalho não têm, de modo algum, para ele, o sentido de tecer, de fiar, de perfurar etc., mas representam unicamente o meio de ganhar o dinheiro que lhe permitirá sentar-se à mesa, ir ao bar, deitar-se na cama" ${ }^{\prime 10}$. Esta alienação também se manifesta no polo social oposto. Para o comerciante de minerais, Marx observa, minerais não possuem o significado pessoal de minerais.

A abolição das relações de propriedade privada acaba com esta oposição entre significado e significado pessoal na consciência dos indivíduos; mas a discrepância entre eles permanece.

A necessidade desta discrepância está implicada na profunda pré-história da consciência humana, na existência, entre animais, de dois tipos de sensibilidade que mediam seus comportamentos no ambiente objetivo. Como sabemos, a percepção do animal é limitada às influências que possuem uma conexão baseada em sinais com a

\footnotetext{
${ }^{10}$ Karl Marx, Trabalho Assalariado e Capital \& Salário, Preço e Lucro. $2^{\mathrm{a}}$ ed. São Paulo: Expressão Popular, 2010, p. 36.
}

\begin{tabular}{|c|c|c|c|c|}
\hline Qevista Dialectus & Ano 2 & n. 4 & Janeiro-Junho 2014 & p. $184-210$ \\
\hline
\end{tabular}


satisfação de suas necessidades, mesmo que tal satisfação seja somente eventual ou possível $^{11}$. Mas, necessidades podem desempenhar a função de regulação mental somente quando elas agem como objetos motivacionais (incluindo os meios de adquirir tais objetos ou se defender deles). Em outras palavras, na sensorialidade dos animais, as propriedades externas dos objetos e suas habilidades para satisfazerem certas necessidades não estão separadas uma da outra. Como sabemos, a partir do famoso experimento de Pavlov, um cachorro responde à influência do estímulo condicionado por comida ao tentar alcança-la e lambe-la ${ }^{12}$. Mas o fato de que o animal não é capaz de separar a percepção da aparência externa do objeto das necessidades que ele experimenta, não implica, de maneira alguma, sua completa coincidência. Pelo contrário, no decurso da evolução de suas conexões se tornam cada vez mais móveis e extremamente complexas; somente sua separação uma da outra permanece impossível. Tal separação ocorre somente no nível humano, quando significados verbais cavam um fosso entre as conexões internas de dois tipos de sensibilidade.

Eu tenho usado o termo cavar um fosso (embora talvez tenha sido melhor dizer "intervêm") somente para acentuar o problema. Na verdade, em suas existências objetivas, isto é, como fenômenos da consciência social, significados refratam objetos para o indivíduo independentemente de seus relacionamentos com a vida dele, necessidades e motivos dele. A palha cujo homem que está se afogando se agarra permanece em sua consciência como uma palha, independentemente do fato de que esta palha, se apenas como uma ilusão, adquire para ele naquele momento o significado pessoal de um meio de resgate.

Nos estágios iniciais da formação da consciência, significados objetivos fundem com significado pessoal, mas já existe uma discrepância implícita nesta unidade que inevitavelmente assume sua própria forma explícita. É isso que torna necessário distinguir significado pessoal em nossa análise como ainda outro "elemento formativo" do sistema de consciência individual. São esses significados pessoais que criam o que L. Vigotski chamou de plano "escondido" da consciência, que é frequentemente interpretado na psicologia não como um elemento formativo na atividade do sujeito, no desenvolvimento de sua motivação, mas como algo que é supostamente uma expressão

\footnotetext{
${ }^{11}$ Este fato deu a certos escritores alemães terreno para fazerem uma distinção entre ambiente (Umwelt), como aquele que é percebido por animais, e o mundo (Welt) que é percebido somente pela consciência humana.

${ }^{12}$ Ver Ivan Petrovich Pavlov, Collected Works, vol. 3, book 1, Moscow 1951, p. 151.
}

\begin{tabular}{|l|l|l|l|l|}
\hline Qevista Dialectus & Ano 2 & n. 4 & Janeiro-Junho 2014 & p. 184-210 \\
\hline
\end{tabular}


direta das forças essenciais, intrínsecas, originalmente implantadas na própria natureza humana.

$\mathrm{Na}$ consciência individual,os significados assimilados de fora se separam, por assim dizer, e ao mesmo tempo unem os dois tipos de sensibilidade: as impressões sensoriais da realidade externa na qual a atividade do sujeito procede, e as formas de experiência sensorial de seus motivos, a satisfação ou não-satisfação das demandas que residem por trás deles.

Em contraste aos significados objetivos, os significados pessoais, como o tecido sensorial da consciência, não têm existência "supra-individual", não-psicológica. Enquanto que a sensorialidade externa associa significados objetivos com a realidade do mundo objetivo na consciência do sujeito, o significado pessoal os associa com a realidade de sua própria vida neste mundo, com suas motivações. É o significado pessoal que dá à consciência humana sua parcialidade.

Já mencionamos o fato de que significados são "psicologizados" na consciência individual quando eles retornam para a realidade sensorialmente dada do mundo. Outro fator, e, além disso, decisivo, que torna os significados objetivos em uma categoria psicológica é o fato de que, por funcionar no sistema da consciência individual, eles realizam não eles mesmos, mas o movimento do significado pessoal que encarna si mesmo neles, o significado pessoal que é o ser-por-ele-mesmo do sujeito concreto.

Psicologicamente, isso quer dizer, no sistema da consciência do sujeito, e não como seu tema ou produto, significados em geral não existem exceto na medida em que eles realizam certos significados pessoais, assim como as ações e operações do sujeito não existem exceto na medida em que eles realizam alguma atividade do sujeito evocada por um motivo, uma necessidade. O outro lado da questão reside no fato de que o significado pessoal é sempre o significado de algo, um significado "puro", sem objetivo, é tão sem sentido quanto uma existência sem objetivo.

A encarnação do significado pessoal em significados objetivos é um processo profundamente íntimo, psicologicamente significante e, de forma alguma, automático ou instantâneo. Esse processo é visto em toda sua plenitude em trabalhos de literatura e na prática da educação moral e política.

É mais claramente demonstrada nas condições da sociedade de classes, no contexto da luta ideológica. Neste contexto, os significados pessoais refletem os motivos engendrados por relacionamentos vivos de uma pessoa real podem falhar em encontrar significados objetivos que os expressem plenamente, e eles então começam a

\begin{tabular}{|c|c|c|c|c|}
\hline Qevista Dialectus & Ano 2 & n. 4 & Janeiro-Junho 2014 & p. $184-210$ \\
\hline
\end{tabular}


viver em roupas emprestadas, por assim dizer. Imagine a contradição fundamental que essa situação acarreta. Em contraste à sociedade, o indivíduo não tem uma linguagem especial sua com significados que ele desenvolveu por si mesmo. Sua compreensão da realidade pode ocorrer somente por meios dos significados "não originais" que ele assimila de fora - o conhecimento, conceitos e visões que ele recebe através de relações, nas várias formas de comunicação individual e de massa. É isso que torna possível introduzir em sua consciência ou até mesmo impor sobre essa consciência noções ou ideias distorcidas ou fantásticas, incluindo aquelas que não têm base na experiência viva prática, real, mas, ao mesmo tempo, tendo alguns estereótipos, eles adquirem a capacidade de qualquer estereótipo de resistir, de modo que somente os grandes confrontos da vida podem quebra-los. Mas, até mesmo quando eles são quebrados, a desintegração da consciência, sua inequidade, não é removida; nela mesma a destruição dos estereótipos causa somente uma devastação que pode levar a um desastre psicológico. Deve haver também uma transformação dos significados pessoais subjetivos na consciência do indivíduo em outros significados objetivos que adequadamente os expressem.

Uma análise mais de perto desta transformação dos significados pessoais em significados objetivos adequados (ou mais adequados) mostra que isso ocorre no contexto da luta pela consciência das pessoas que é travada na sociedade. Por isso eu quero dizer que o indivíduo não "para" simplesmente em frente a uma exibição de significados,onde ele tem somente que fazer sua própria escolha, que estes significados - noções, conceitos, ideias - não esperam passivamente sua escolha, mas explodem agressivamente em suas relações com as pessoas que formam o círculo de sua verdadeira relação. Se o indivíduo é forçado a escolher em certas circunstâncias, a escolha não é entre significados, mas entre as posições sociais conflitantes expressas e compreendidas através desses significados.

Na esfera das noções ideológicas, este processo é inevitável e universal somente na sociedade de classes. Mas, de uma maneira ela continua a estar ativa em qualquer sistema social, porque as características específicas da vida do indivíduo, as características específicas de suas relações pessoais, ligações e situações também sobrevivem, porque suas características especiais como um ser corpóreo e certas condições externas específicas que não podem ser identificadas por todos permanecem únicas.

\begin{tabular}{|c|c|c|c|c|}
\hline Qevista Dialectus & Ano 2 & n. 4 & Janeiro-Junho 2014 & p. $184-210$ \\
\hline
\end{tabular}


Não existe desaparecimento (nem poderia existir) da discrepância constantemente proliferante entre significados que carregam a intencionalidade, a parcialidade da consciência do sujeito, e os significados objetivos, que, apesar de “indiferentes" a eles, são os únicos meios pelos quais os significados pessoais podem ser expressos. É por isso que o movimento interno do sistema desenvolvido da consciência do indivíduo está cheia de momentos dramáticos. Estes momentos são criados por significados pessoais que não podem "expressar a si mesmos" em significados objetivos adequados, significados que foram destituídos de suas bases em vida e, portanto, algumas vezes agonizando, desacreditam si mesmos na consciência do sujeito; tais momentos também são criados pela existência de motivos ou objetivos conflitantes.

Não precisa ser repetido que este movimento interno da consciência do indivíduo é engendrada pelo movimento da atividade objetiva de uma pessoa, que por trás dos momentos dramáticos da consciência reside os momentos dramáticos de sua vida real, e, que por essa razão, uma psicologia científica da consciência é impossível sem a investigação da atividade do sujeito, as formas de sua existência imediata.

Em conclusão, eu sinto que devo tocar em um problema que algumas vezes é chamado de "psicologia da vida", a psicologia da experiência, que mais uma vez é discutida na literatura. A partir do que foi dito neste artigo, segue que, embora uma psicologia científica nunca deve perder de vista o mundo interior do homem, o estudo deste mundo interior não pode estar divorciado de um estudo de sua atividade e não pode constituir qualquer tendência especial da investigação psicológica científica. O que chamamos experiências são os fenômenos que surgem na superfície do sistema de consciência e constituem a forma na qual a consciência está imediatamente aparente para o sujeito. Por essa razão, as experiências de interesse ou tédio, atração ou dores de consciência, não revelam por si mesmos suas naturezas para o sujeito. Embora elas pareçam ser forças internas estimulando sua atividade, suas funções reais são somente para guiar o sujeito em direção a suas fontes verdadeiras, para indicar o significado pessoal dos eventos que ocorrem em sua vida, para compeli-lo a parar por um momento, por assim dizer, o fluxo de sua atividade e examinar os valores essenciais que se formaram em sua mente, para assim encontrar si mesmo neles, ou, talvez, revisá-los.

Para resumir, a consciência do homem, como sua atividade, não é aditiva. Não é uma superfície plana, nem mesmo uma capacidade que pode ser preenchida com imagens e processos. Também não são as conexões de seus elementos separados. É o

\begin{tabular}{|c|c|c|c|c|}
\hline Qevista Dialectus & Ano 2 & n. 4 & Janeiro-Junho 2014 & p. $184-210$ \\
\hline
\end{tabular}


movimento interno de seus "elementos formativos" orientados a um movimento geral da atividade que afeta a vida real do indivíduo na sociedade. A atividade do homem é a substância de sua consciência. 